\title{
Using Information And Communication Technologies To Improve Transparency In Transition Countries
}

\author{
Mysore Ramaswamy \\ Southern University, Baton Rouge, Louisiana, USA
}

doi: 10.19044/esj.2016.v12n11p1 URL:http://dx.doi.org/10.19044/esj.2016.v12n11p1

\begin{abstract}
Automating government to citizen (G2C) interactions will help in achieving transparency and combating corruption. However, in the case of post-communist transitioning countries such as Armenia, the challenges are unique. These countries are struggling with the transformation of their legacy bureaucratic and administrative processes. In addition, almost every postSoviet country has inherited systemic corruption that is built in to the 'modus operandi' of both the public and private sectors. The process of automating G2C interactions using information and communication technology (ICT) needs to be analyzed as a socio-technical information processing system. Automating existing bureaucratic processes that are defective will not yield results. Improving the enforcement of rules through automation is clearly the best way to combat corruption. The introduction of e-Government plays a major role in this context as it automates several processes. To deliver public service in a more transparent and efficient way, it is necessary to categorize, assess, and modify existing administrative processes. In this paper, we propose a methodology to render transparency in governance using information and communication technology that goes beyond mere automating existing citizen-government interactions.
\end{abstract}

Keywords: e-Government, Information and Communication Technology, Post-Communist Transition, Process Restructuring, Public Sector Corruption, Transparency

\section{Introduction}

Post-communist transitioning countries such as Armenia have inherited endemic corruption. Recent innovations in information and communication technology (ICT) have given hope to the idea that new technologies in the form of e-government systems can be used to combat corruption in the public sector. Most governments across the world desire their citizens and businesses to interface with them through electronic means 
for the obvious reasons of efficiency in cost-saving and effectiveness. However, whether the transparency in process and information-sharing that this presupposes is also an equally important social and cultural objective for all leaders is a less obvious assertion. As Jane Fountain (2001) states in her work, there is a certain element of the 'perversity of incentives' to acknowledge here; Kedzie calls this the "Dictator's Dilemma" in the state (Allison, 2002; Carbo, 2004) - where increased efficiency and political efficacy (brought about by ICTs) are positively related to each other, and negatively related to authoritarian and highly centralized control.

This is especially true in developing countries where the newly emerging bureaucracies are hesitant to give way to automated systems (Heeks, 2003). These technologies can serve a variety of different ends: better delivery of government services to citizens, improved interactions with business and industry, citizen empowerment through access to information, or more efficient government management. The resulting benefits can be less corruption, increased transparency, greater convenience, revenue growth, and/or cost reductions. Analogous to e-commerce, which allows businesses to transact with each other more efficiently (B2B) and brings customers closer to businesses (B2C), e-government aims to make the interaction between government and citizens (G2C), government and business enterprises (G2B), and inter-agency relationships (G2G) more friendly, convenient, transparent, and inexpensive.

The term 'e-government' refers to the application of Information and Communication Technology (ICT) by government agencies In this paper, we prefer to use the term "e-governance" in a broader sense to include a deeper understanding of the way ICTs impact the existing (and potential future) interactions between a government and its constituents. In other words, egovernance goes beyond the 'what' of an e-government interaction that presumably delivers service to a constituent - and includes rather an analysis of the 'how' and 'why'. We note that one cannot improve upon something in automation that is not already rational and functional in current daily practice. The term 'transparency' is used in this paper to mean disclosure or openness regarding all transactions with public agencies. This is a necessary precursor for the eradication of corruption.

This paper is organized as follows. First we discuss the need for transparency in government-constituent interactions. Issues related to postcommunist transition in countries such as Armenia are discussed next. This is followed by an analysis of socio-technical factors. A framework for improving transparency is introduced next. Concluding remarks form the last section. 


\section{Need for Transparency}

The need to have better transparency is not restricted to the Western countries. In fact, it is more urgently required in developing countries. To a large extent this presumes that the realization of coherent public diplomacy is contingent upon a state's ability to build itself a back-end capable of effectuating its own communication systems. Data-intensive collaborations at some point involve the issue of data ownership (Bovens, 2005; Koss, 2001). Such issues in a fledgling bureaucracy can be a potential stumbling block especially in government to government (G2G) transactions. In the same way that intelligence agencies in the United States post 9/11 discovered the major flaws in the ability of their respective vast systems to dovetail and cooperate effectively, so too do the various branches of government and their respective ministries face a challenge of interoperability. In addition, it is important to determine whether there are any institutionalized means of process review or opportunities for constituents to address their grievances. By developing the infrastructure and capacity to provide local service and service delivery, e-government can become a mechanism for spurring community involvement and thus become a catalyst for direct political interaction and/or e-participation (Clark, 2003). Naturally, this may be viewed with skepticism by various parts of the bureaucracy. In the context of developing countries, this is further exacerbated by the subservience of bureaucracy to political authority and the 'strongmen' that are frequently its human face.

In developing countries, the issues of sustainability and ownership are critical; there is a strong tendency for projects to dissolve or disappear completely after funding runs out, in part because ownership and commitment by government figureheads and organizations is not always successfully assumed (Homburg, 2002). Moving toward institutional transparency does not necessarily serve the purpose of those who do not suffer the institutional status quo. The extent to which e-government projects could facilitate political participation is a social phenomenon that must manifest itself in the physical realm before it can extend to the virtual realm. In other words, the social reality of a political culture characterized by "unpleasant" interactions with all levels of public administration can easily transcend the objectives of any IT effort to provide the opposite. To provide Online functionality that typifies an advanced polity is to present a solution thirty steps ahead of society. The technology itself can "leapfrog" various steps and standards, but should not be geared to leaping over public perceptions of "what could work here" and "what could never work here." Every society has its own answer to the question of effective ICT adoption, and in the case of developing countries, workable solutions are often hybrid; combinations of automation and social networking. 
Corruption is the misuse of public power, office or authority for private benefit. This misuse manifests in many ways: bribery, extortion, influence peddling, nepotism, fraud, or speed money. Petty corruption is frequently found where public servants who may be grossly underpaid depend upon small kickbacks from the public to pad their pockets and feed their families. Grand corruption involves high officials who make decisions on large public contracts for their personal benefit, or to the benefit of organized, informal groups with highly aligned self-interest as the driver of their cohesion.

In many parts of the world, a major part of the problem in dealing with public sector or government bodies is corruption. No doubt, corruption has been around since time immemorial and indeed, may well be an engrained trait of human nature; nevertheless, most governments and technologists are interested in figuring out what means may be created to combat it. In this context, 'Panoptic Vision' as proposed by Heeks (2003) affords a way to analyze this critical problem. The concept of Panoptic Vision is based on the construct that sees information technology (IT) as a key enabler of management control.

Public corruption can be largely attributed to government intervention in the economy. Therefore, policies aimed at liberalization, stabilization, deregulation, and privatization can sharply reduce the opportunities for corruption (Al-Mashari, 2001; Alter, 2002). Where government regulations are pervasive, onerous or imprecise, and when government officials have discretion in applying them, individuals are often willing to offer bribes to officials to circumvent rules.

High levels of corruption are present where institutional mechanisms to combat corruption are weak or not used, and where a system of simple internal checks and balances does not exist. In such cases, entrenched political elite dominates and exploits economic opportunities, manipulating them in return for personal gains (Fountain, 2001). The significance and impact of corruption varies greatly across the world. Even though people may tolerate demands for small payments in return for official services such as the issuing of permits and licenses, they do not necessarily approve. They perceive it simply as the most painless, quick and workable way of obtaining things they want or need.

Typically, in a bureaucracy, discretion is structured by rules and standard operating procedures, and it does allow civil servants to take into consideration contextual variations and act according to other norms (Keil, 2003). It has to be ensured that the uniquely human ability to act on broader societal norms is retained after ICT intervention in bureaucratic practices. The real challenge is to figure out how to modify practices that work in Western countries, so that they can work in transition/developing countries 
where there is no culture of accountability and transparency in any type of constituent-government interactions.

Cucciniello (2012) describes a framework to monitor the degree of transparency based on four dimensions: institutional, political, financial, and service delivery. This model was designed to measure government transparency based on the information published on their institutional websites. The institutional dimension aims to capture the degree of transparency with regard to the government's mission and operations, its institutional activities and the information it is obliged to publish by law. The political dimension aims to capture the degree of accessibility of information on political representatives, their political mandate and activities and other information, such as absenteeism at council meetings and salary. The financial dimension aims to assess the degree of transparency with regard to the use of financial resources, the solvability of governments and other financial issues. The service delivery dimension aims to assess the degree of transparency concerning the performance of governments in the delivery of services to citizens and businesses. Each dimension of the assessment framework is divided into different variables and assessed using specific measurements and checklists.

Each of the variables of the different dimensions is evaluated with reference to two factors: accessibility and interactivity. Three different types of information are relevant in this context: static information, dynamic information, and feedback information. Static information is information about the public agency and its mission, how it functions, and what it offers. This type of information does not change frequently and some of this information is required to be published in order to comply with existing regulations. Dynamic information consists of information about performance for each of the four dimensions stated above. Feedback information comprises performance-related feedback information.

E-Government Transparency Index (Freed, 2011) was developed in 2009 to address the following issues: a) Creating an accurate, actionable, and precise measurement of citizens' opinions on government transparency and b) Quantifying the relationships among online transparency, citizen satisfaction, trust, and the likelihood of participating and collaborating with government agencies. These indices are developed based on surveys conducted with randomly selected visitors to various government websites. Questions were asked about their experience with and perceptions of the different elements of the website. The objective is to gather information that answers the following questions: how thorough the information on the website is, how accessible it is, and how quickly it is made available. 


\section{Post-Communist Transition}

A destructive legacy of Soviet rule for most successor states of the former Soviet Union has been widespread corruption. In the case of Armenia, the smooth transition of power in the early 1990s has allowed its political leaders to use corruption to consolidate firm control over the state apparatus (Olson, 2000; Ramasoota, 1998). However, Armenia's economy has fared relatively well under a more centralized form of endemic corruption, albeit its concentration on largely donor driven projects.

To derive a more comprehensive perspective of the context in which the e-governance transformation in Armenia is being attempted, it is necessary to undertake a brief analysis of the period of Soviet domination. This period was characterized by a highly centralized political culture and a well-defined bureaucracy driven by elite (Wang, 2001; Wimmer, 2001). There was minimal government to citizen (G2C) interaction and hardly any effective mass political participation or a demand for it. All of this changed after the collapse of the Soviet Union in 1991.

The post-independence or transition period of Armenia started with the disruption of institutional stability and resulted in a deterioration of existing bureaucratic procedures. This has resulted in an environment of ill-defined and poorly-adhered to protocols for government-to-constituent interactions (Stefes, 2006). The provision of clear information for the public, and moreover the public's right to it, are heretofore newly explored concepts. Before we can identify areas suitable for e-governance implementation, it is vital to ensure that a clearly defined and understandable procedure for reform is in place. Process restructuring becomes critical in this context.

Barriers to change are identified in the following four areas: Organizational Characteristics, Human Capacity, Financial Capacity, and Technical Infrastructure. Organizational characteristics such as the existence of local information technology (IT) departments that address questions of automation and efficiency, and the existence of collaboration between IT and public relations (PR) departments which results in the availability of streamlined public information are vital to the transformation process. To a large extent this presumes that the realization of coherent public diplomacy is contingent upon a state's ability to build itself a back-end capable of effectuating its own communication systems. Data-intensive collaborations at some point involve the issue of data ownership (Bremmer, 1997). Such issues in a fledgling bureaucracy can be a potential stumbling block especially in government to government (G2G) transactions. In the same way that intelligence agencies in the United States post 9/11 discovered the major flaws in the ability of their respective vast systems to dovetail and cooperate effectively, so too do the various branches of government and their respective ministries face a challenge of interoperability. In addition, it is important to 
determine whether there are any institutionalized means of process review or opportunities for constituents to address their grievances. By developing the infrastructure and capacity to provide local service and service delivery, egovernment can become a mechanism for spurring community involvement and thus become a catalyst for direct political interaction and/or e-participation (Heeks, 2003; Moore, 1997). Naturally, this may be viewed with skepticism by various parts of the bureaucracy. In the context of post-communist societies, this is further exacerbated by the subservience of bureaucracy to political authority and the 'strongmen' that are frequently its human face (Selian, 2005).

The human capacity component in an institution is critical to the ability and capacity of that institution to evolve. For the purposes of this analysis, this component can be used interchangeably with the notion of social capital even in the limited parameters of a single institution. Social capital refers to the 'stock' that is created when a group of departments or divisions develop the ability to work together and create linkages for mutually productive gain. Agents in a collaborative network, even within one institution, learn of new technologies, opportunities, challenges, and the outcome of transactions more quickly because of the density of interaction within the network (Scholl, 2003). Vertically organized networks, like the kind we find in the case of Armenia, tend toward characteristics that adversely affect this sort of 'mesh' learning about information processing capacity by virtue of a lack of density and 'flatness' in the nodes of the social networks that drives the political apparatus. This is an interesting point to consider because whereas complexity in networks may traditionally be associated with building up a sclerosis of sorts in an institutional body in terms of its ability to act, it can be suggested that a lack of complexity in an overly simple hierarchical network structure can equally result in a lack of clear action and effectiveness.

The financial barrier also is a critical one to the emergence of innovation and institutional transformation. This is largely about the creation of incentives for people to innovate. As it stands, the average salaries in IT departments of ministries in Armenia are quite low compared to the comparable private sector jobs, and do not create an environment conducive to innovation. The most critical element here is a lack of commitment from the top - strategic and financial - to the objectives of institutional transformation. The status quo suits the purposes of many.

Barriers posed by technical infrastructure refer to problems of depreciating equipment, lack of standardization and interoperability, an overall disregard for licenses, and an unwillingness to capitalize on telecommunication infrastructure even when it is present (i.e. as in the case of the purported 'dark' fiber running through most major government buildings). 
This creates an environment where change is not a priority, and where complacency becomes a rule.

In the context of e-inclusion, under the category of transaction services, government-to-citizen interactions of e-Government become very significant. In order to build a more inclusive e-society, we need to address these questions:

- How can we make e-Government truly citizen-centric?

- Do we have objectives that are correct and realistic? effectively?

- How well are we achieving these objectives fully and cost

- Are these objectives jointly determined and agreed upon by the citizens and the government agencies?

We need better models of the processes used to plan, fund, develop, implement, operate, and evaluate successful e-Government in various political and social, cultural, and economic contexts (Allison, 2002).

Although technology can create new or modified business practices at a rapid rate, successful adoption of new best practices must stand up to market forces. Technology and the marketplace are continually reshaping business activities and as a consequence, business strategies. An organization must continually work towards an alignment that fits into the organization's business strategy, IS strategy, ethical advancement and compliance strategies. This alignment should improve the likelihood that IS initiatives are explicitly linked to areas that are critical to successful business performance, provide a source of competitive advantage and ensure ethical compliance. The process of aligning strategies should heighten management's awareness and use of information systems to better support organizational goals, objectives, and ethical compliance. The role of IS should be that of a strategic enabler for competitive success, rather than just an operational supporter.

\section{Socio-technical Factors}

Socio-technical factors pertain to exacerbated accountability dysfunctions that can occur as a consequence of automation (Keil, 2003). According to Bovens (2005) the major categories of dysfunctions are: Ruleobsession, Proceduralism, Rigidity, and Scapegoating.

Rule-obsession or Output-obsession refers to the focus on outcomes over process. 'Proceduralism' refers to increased emphasis on procedures to avoid responsibility and accountability. Strict adherence to procedures cam render the bureaucracy to lose the ability to balance procedures with public values. Relying heavily on encoded computer procedures can undermine the effectiveness of public sector organizations. 
The ability to take contextual variations into account is affected by the encoding of procedures which actually results in encoding rigidity. After developing a system, the embedded rigidity can make it difficult to modify as part of organizational learning. As a result of the introduction of ICTs in the public sector, there has been a displacement of accountability from bureaucrat to software engineer. When things go wrong, the tendency is to use the computer as a scapegoat. It is important to consider these sociotechnical factors while building e-government systems in order that the citizens can have confidence in automated systems.

The degree of automation can vary across a wide range. Smith (2010) states a scale of nine degrees of automation starting from the first level where the computer offers no assistance to the ninth level where the computer decides everything. In between these extremes, there are several levels where a varying degree human-computer interaction occurs. The appropriate level of ICT intervention depends on the particular interaction that has to be automated.

The need for transparency and accountability calls for automated systems. But in developing countries, where there is no culture of established bureaucracy, there is also a concomitant need for accommodating sociocultural factors. An analysis of the existing bureaucratic practices in transition countries indicates two areas that need attention. The first pertains to the availability of information regarding governmental procedures to the general public. Acquiring such information is quite simple in most western societies. But in some developing countries government officials, especially at the lower levels, make it harder for the public to execute these transactions so their reliance on the officials who "sell" this information and "facilitate" the required transaction is not diminished. The roots of public sector corruption are found in such opportunities. The second area of concern is the convoluted way in which governmental procedures in general are laid out. In many countries, several layers of authority are embedded in the bureaucratic system. Efforts to build a congruous system to replace it have yet to emerge. This gives an opportunity for government officials to use the system to their advantage. Clearly, the simplification and clarification of procedures has not been their priority (Homburg, 2002). This elucidates the point that process restructuring should also accompany a concomitant improvement in the work and incentive conditions of the government employees delivering public service. This necessitates the emergence of an environment in which all participants have a share in the benefits of modern technology.

A critical component in the multilayered process of rendering transparency pertains to the availability of digital content that users can access. User interactions with digital or electronic means have been grouped in a number of ways (Kuzmin, 2003; Mistry, 2005). In the present analysis, it 
will be useful to categorize them in the following way: information services, communication services, and transaction services. An inclusive and accountable bureaucracy has to provide more useful digital interactions to a larger segment of society, especially in the third category of transaction services (Carbo, 2004; Lee, 2003).

There is little apparent understanding as to where the main impact of ICTs will be, and this is manifested by an obvious collective misunderstanding as to what e-government should accomplish. The development of ICTs in government - to support both back-end and frontend systems - should come not only from the united front of a coordinated and coherent donor stream, but in conjunction with genuine efforts to promote organic (as opposed to transplanted) growth strategies (Homburg, 2002). Anything less will result in a continued flow of ineffective funding that misses the mark in terms of meeting the objectives of true institutional transformation, which in large part - and with few exceptions - describes the status quo in many developing countries today.

\section{A Framework for Improving Transparency}

Clearly, ICT can play a critical role in bringing transparency in government to citizen (G2C) interactions. Automating existing bureaucratic procedures, per se, will not yield transparency. As Michael Hammer, a wellknown business consultant who championed business process reengineering, wrote an article in Harvard Business Review titled "Don't Automate, Obliterate.” He stresses the importance of simplifying processes, eliminating non-value added tasks, and innovating to improve speed, quality, and service. No meaningful improvements can be expected by simply automating the existing inefficient processes. This is especially true for developing countries.

We propose a four stage framework that will improve transparency by implementing e-government applications. In the first stage, the existing procedures are viewed through the lens of Transparency Assessment Framework the details of which were stated an earlier section. At the end of this stage, we will have a set of critical processes that need intervention. In the second stage, we examine the selected processes from the view of sociotechnical factors. At the end of this stage we will have processes that are free from Rule-obsession, Proceduralism, Rigidity, and Scapegoating. In the third stage, we restructure the processes to make interactions more efficient and effective. In the final stage, we automate the restructured processes.

In the first stage, existing government-constituent interactions are examined. The number of interactions is indeed very large as evidenced by the three stakeholder groups of constituents (citizen, business, and government). The gamut of interactions is also very diverse. The analysis is 
conducted along the four dimensions (institutional, political, financial, and service delivery) and the interactions are categorized based on the degree of perceived importance by the constituents. Socio-technical factors are considered in the second stage. Before manual procedures are automated, it has to be ensured that there are no problems such as rule-obsession and proceduralism. Not only will this help towards transparency, but it will also make acceptance by constituents easier.

Processes are restructured in the third stage. Automating legacy procedures that afforded plenty of opportunities for inefficiency and corruption will not yield results. The main objective of restructuring various processes before transforming them into digital interactions is to improve the effectiveness of bureaucracy as a system and make it more transparent. It is to be noted that placing an IT layer over and automating a faulty bureaucratic system may yield a more efficient system, but will certainly not be one desired by or responsive to its core constituents, and will not help in any way to combat corruption or perceptions of it. When automated processes result in disintermediation, it is necessary that the relevant entities are on board with new procedures. After completion of the restructuring stage, we are ready for implementing in the fourth and final stage.

This framework also provides a means of evaluating an extensive (if not comprehensive) series of government-constituent interactions. Depending upon the value of the parameters of the given transaction, we are able to make inferences on the potential of that transaction for potential of ICT intervention. This naturally opens up a wide arena of analysis, particularly for others who wish to specialize and focus specifically on the dynamics and characteristics of specific interactions where ICT intervention is useful.

\section{Conclusion}

The basic building blocks of e-government are interactions between the government and its constituents. Changing the bureaucratic methods and human attitudes of those 'running the system' in post-soviet transition countries is doubly challenging. These countries suffered the first shock during the total collapse of public administration when the Soviet Union disintegrated. Now, the nascent bureaucracy considers automating G2C interactions as a second shock. The success of e-Government initiatives to improve transparency and combat public sector corruption will ultimately depend upon the acceptance of ICT among its citizens. The critical steps in using ICT in public sector bureaucracy consist of rendering digitized versions of interactions between the government and its constituents. In this paper, we have presented a framework that can identify and categorize dealings of the public along different dimensions. Restructuring the 
bureaucratic procedures and then automating them in a systematic way as suggested in this paper affords a practical approach to render transparency and accountability to public sector. Measures such as e-Government Transparency Index will help in evaluating the success of these measures. Future work in this area focuses on developing a comprehensive framework that will enable policy makers and researchers to point out the potential priority areas that need to be automated first to render accountability and transparency, and also yield a realistic estimate of resources needed to achieve such transformation. In addition, such an approach will also help in giving a better insight into process restructuring.

\section{References:}

Allison, Juliann Emmons. (2002). Technology, Development, and Democracy: International Conflict and Cooperation in the Information Age. Albany: State University of New York Press.

Al-Mashari, Majed, Zahir Irani, \& Mohamed Zairi. (2001). Business process reengineering: a survey of international experience. Business Process Management Journal, December 2001, pp. 437-455.

Alter, S. (2002). Information Systems: Foundations of E-Business. Prentice Hall, Upper Saddle River, NJ.

Amyan, M. M. et al. (2016). The Effective Utilization of Knowledge Management in E-Government. European Scientific Journal, Vol. 12, No. 2, pp. 290-308.

Berghel. Hal. (2005). The Two Sides of ROI. Return on Investment Vs. Risk of Incarceration. Communications of the ACM. 48.4. pp. 15-20.

Bovens, M. (2005). Public Accountability. The Oxford Handbook of Public Management, Oxford University Press, pp. 182-208.

Bremmer, Ian and Cory Walt. (1997). Armenia's New Autocrats. Journal of Democracy, No. 8 (July), pp. 77-91.

Carbo, T. and Williams, J. (2004). Models and Metrics for Evaluating Local Electronic Government Systems and Services. The Electronic Journal of Electronic Government, Vol. 2, No. 1, pp. 99-106.

Carbo, T. and Williams, J. G. (2004). Some Determinants of User Perceptions of Information Quality on the World Wide Web. Electronic Journal of e-Government, Vol. 2, No. 2 pp. 94-105.

Choi, S. et al. (1997). The Economics of Electronic Commerce, Macmillan Technical Publishing, Indianapolis.

Clark, K. and Baker, P. (2003). Municipal Advanced Telecommunication Infrastructure Project (MuniTIP). Georgia Center for Advanced Telecommunications Technology, OTP Policy Study No. 50103.http://www.gcatt.org/otp/papers/ MuniTIP.pdf 
Cucciniello, Maria et al. (2012). Assessing Transparency in Government: Rhetoric, Reality, and Desire. Proceedings of the $45^{\text {th }}$ Hawaii International Conference on Information Systems, (11 pages).

Fountain, Jane E. (2001). Building the Virtual State: Information Technology and Institutional Change. Washington, DC: Brookings Institution Press.

Freed, Larry. (2011). Quantifying the Impact of Transparency. http://www.nrc.gov/public-involve/open/evaluating-progress/foreseetransparency-index.pdf

Grimsley, M, Meehan, A, Sen Gupta, K (2006). Evaluative Design of eGovernment Projects: A Public Value Perspective. Proceedings of the Twelfth Americas Conference on Information Systems, Acapulco, Mexico August $04^{\text {th }}-06^{\text {th }} 2006$.

Heeks, R (2003). Causes of e-Government Success and Failure: Design Reality Gap Model. http://www.e-devexchange.org/ eGov/ causegap.htm Homburg, V. and Bekkers, V. (2002). The Back-Office of E-Government. Proceedings of the $35^{\text {th }}$ Hawaii International Conference on Information Systems, (9 pages).

Keil, M. et al. (2003). Bridging the Digital Divide: The Story of the Free Internet Initiative in LaGrange, Georgia. Proceedings of the $36^{\text {th }}$ Hawaii International Conference on Information Systems, (10 pages).

Koss, F. A. (2001). The Challenges of redressing the digital divide. Journal of International Affairs, 55 (1), 75-90.

Kuzmin, A. (2003). The Two Dimensions of e-Government: Potential and Use.

Government.pdf www.processconsulting.ru/doc/Two_ dimensions_of_eLee, $\mathrm{H}$. et al (2003). The growth of broadband and electronic commerce in South Korea: Contributing factors. Information Society, 19 (5), 81-93.

Mason, S. M. et al (2003). Applying communication theory to digital divide research. IT and Society, 1 (5).

Mistry, J. J. (2005). A conceptual framework for the role of government in bridging the digital divide, Journal of Global Information Technology Management, 8 (3), 28-46.

Moore, M. (1997) Creating Public Value: Strategic Management in Government. Cambridge, MA: Harvard University Press.

Naarmala, J. (2004). "Going Digital - Explaining Dimensions of eGovernment," www.ebrc.info/ pages_ C86FCC04-3314-4DF9-9AE2138286 0CB17F.asp

Olson, M. (2000) Power and Prosperity: Outgrowing Communist and Capitalist Dictatorships. New York, NY: Basic Books.

Osman, I. H. et al. (2014). I-MEET Framework for the Evaluation of EGovernment Services. European Scientific Journal, pp. 17-29. 
Ramasoota, P. (1998). Information Technology and Bureaucratic Surveillance. Information Technology for Development, Vol. 8, No. 1, pp. 51-64.

Ramaswamy, M and Selian, A. (2007). e-Government in Transition Countries: Prospects and Challenges. Proceedings of the $40^{\text {th }}$ Hawaii International Conference on Information Systems, (10 pages).

Scholl, H. J. (2003). E-Government: A Special Case of ICT-enabled Business Process Change. Proceedings of the $36^{\text {th }}$ Hawaii International Conference on System Sciences, (12 pages).

Selian, A. (2005). The Use of ICT as Tools for Institutional Transformation in Armenia. Armenian Journal of Public Policy, Vol. 2, No. 1, pp. 91-111.

Smith, M. L., et al. (2010). Automating the Public Sector and Organizing Accountabilities. Communications of the Association for Information Systems, Vol. 26, Article 1.

Stefes, Christoph. (2008). Governance, The State, and Systematic Corruption: Armenia and Georgia in Comparison. Caucasia Review of International Affairs, Vol. 2, No. 2, pp. 73-83.

Wang, H. and J. Rosenau. (2001). Transparency International and Corruption as an Issue of Global Governance. Global Governance, No. 7, pp. 25-49.

Wimmer, M. R. et al (2001). Electronic Business Invading the Public Sector: Considerations on Change and Design. Proceedings of the $34^{\text {th }}$ Hawaii International Conference on System Sciences, (10 pages).

Zmud, R. W. (1978). "An Empirical Investigation of the Dimensionality of the Concept of Information,” Decision Sciences (9), pp. 187-195. 